\title{
Risk of cervical cancer associated with HPV infection among the gynae outdoor patients
}

\author{
T Rahman', S Tabassum², M Jahan³
}

\begin{abstract}
Human papilloma virus is an oncogenic DNA virus, which is identified in $99.7 \%$ case of invasive cancer. It is the most prevalent virus involved in sexually transmitted diseases worldwide and an important public health challenge for the prevention of cervical carcinoma. Cervical cancer is the second cause of malignant neoplasia and death in women. The present study was thus designed to detect the risk factors for HPV infection in normal and unhealthy cervix of women attending tertiary care hospital (BSMMU). HPV DNA was detected among the study population using the Hybrid Capture 2 assay, which determined HPV high risk types. A total of 68 women between 25-70 years of age were included in this cross sectional study. Among them 13 (19.1\%) cases were tested positive for HPV DNA. The risk factors for HPV infection identified from this result are early sexual activity, lower level of education, early marriage, multi-parity, total duration of sexual activity in years and long term use of oral contraceptive pill and poor socioeconomic condition. Increased awareness and understanding regarding HPV infection would improve the risk of infection and control in sexually active women. $H P V$ diagnosis at early stages of infection is of fundamental importance. The use of HPV test in routine cervical mass screening may not be possible in developing countries like Bangladesh due to its high cost. Nevertheless, it has been shown to be a useful tool when combined with cytology to diagnose high-risk infection in apparently normal tissues, and may help to reduce the risk of cervical cancers. The results obtained from this study ultimately contribute to cervical cancer prevention among Bangladeshi women.
\end{abstract}

Bang Med J Khulna 2013; 46 : 3-6

\section{Introduction}

Worldwide, cervical carcinoma ranks second among the common cancers in women. ${ }^{1}$ Human papilloma virus (HPV) is associated with cervical cancer. This virus is predominantly sexually transmitted and is a high-risk factor for development of cervical carcinoma. ${ }^{2-3}$ Persistent infection with certain genotypes of carcinogenic HPV is associated with nearly all cases $(99.7 \%)$ of cervical cancers. ${ }^{4}$ Among 130 genotypes 16, 18, $31,33,35,39,45,51,52,56,58,59$ and 68 types are "high risk" HPVs. Globally, HPV 16 and 18 contribute to over $70 \%$ of all cervical cancers and HPV types $31,33,35,45,52$ and 58 are responsible for an additional $20 \%$ of cases. ${ }^{5}$

The global incidence of cervical cancer is estimated as $4,70,600$ cases per year with approximately 2,33,400 deaths. ${ }^{6-7}$ Almost $80 \%$ of the cases of cervical cancer occur in the developing countries. ${ }^{6}$ The highest incidence of cervical cancer are observed in Latin America,
Caribbean, sub-Saharan Africa, South and South east Asia. ${ }^{7}$ In the United States, HPV is the most common sexually transmitted infection. ${ }^{8}$ Prevalence of human papilloma virus infection among the general populations varies from $7 \%$ $14 \%$ in India, Bangladesh, Nepal and Sri Lanka. 9 Hospital based statistics indicate that cervical cancer constitutes $22 \%-35 \%$ of the female cancers in different areas of Bangladesh and India. 10-11 HPV prevalence is related to some risk factors of the patients. Demographic, cultural, socioeconomic variables, multiparity, long term contraceptive use, young age at first coitus, multiple sexual partners, low socioeconomic status, low education level, poor genital hygiene, cigarette smoking, genital tract infections etc, are probable co-factors that increase the risk of cervical cancer with HPV infection. ${ }^{12-14}$

Low socioeconomic status has proven to be a significant risk factor for invasive cervical cancer

1 Tanjila Rahman M Phil, Assistant Professor, Dept. of Microbiology, Dhaka Community Medical College \& Hospital 2 Shahina Tabassum PhD, Professor, Dept of Virology. Bangabandhu Sheikh Mujib Medical University, Dhaka

3 Munira Jahan MD, Associate Professor, Dept of Virology. Bangabandhu Sheikh Mujib Medical University, Dhaka 
Bang Med J Khulna 2013; 46

due to its large impact on education and medical resources. 15 In both developed and developing countries, women of low socioeconomic status have a higher risk of cervical cancer. Lower education and higher poverty were found to be associated with increased cervical cancer incidence rates. The increased risk with low socioeconomic status is attributed to a lack of screening, failure to treat precancerous conditions, and lack of knowledge about prevention of HPV infection. ${ }^{16}$

In Bangladesh there is no exact type specific HPVs infections data causing cervical lesion in sexually active women. So, the present study will design to detect the risk factors that are associated with HPV infection in normal and unhealthy cervix of patients attending tertiary care hospital (BSMMU). The information obtained from this study will give new guide lines for cervical cancer screening.

\section{Material and methods}

The prospective study was conducted among 68 women with different types of cervical lesions attending the Obstetrics and Gynecology OutPatients Department (OPD) of Bangabandhu Sheikh Mujib Medical University (BSMMU) Hospital, Dhaka, from January to December, 2008.

Conventional methods are used for diagnosis of cervical lesion of the patients included visible inspection by acetic acid (VIA), colposcopy, histopathology and pap smear tests. Sexually active women above 25 years of age having history of post-coital bleeding, per-vaginal spotting and /or spontaneous bleeding, patients referred for colposcopy due to abnormalities detected on previous pap's smears, VIA test and histopathological examinations, clinically unhealthy looking cervix on per-speculum examination, patients with low-grade squamous intra-epithelial lesions (LSIL) included in this study. Patients were selected after an initial screening using a questionnaire, followed by perspeculum examination by a gynaecologist. After taking informed written consent, cervical specimen for HPV-DNA detection was collected in a cervical sampler consisting of a cervical brush and specimen transport medium (STM), supplied by the manufacturer of HC2 (Digene Corporation, USA). At the Molecular Virology Laboratory of the Dept. of Virology BSMMU, specimens were stored at $-20^{\circ} \mathrm{C}$ until tested. Determination of HPV and estimation of viral load was done by the hybrid capture 2 (HC2) high-risk HPV DNA test kit according to the manufacturer's instructions. ${ }^{17}$ It has detected 13 high-risk HPV types. Cytological and histopathological investigations were conducted at the Department of Pathology, BSMMU by conventional methods. Although serology identifies individuals with current or past infections by HPV, it has limited role in cervical cancer screening purpose. Serological tests are not presently commercialized or standardized.

\section{Results}

The present study was carried out among 68 women attending the Gynecology out patients Department (OPD) of BSMMU Hospital. The age range of the study population was 25 to 70 years (mean: $41.4 \pm 10.6$ years). Out of the 68 women HPV-DNA was positive in $13(19.1 \%)$ and negative in $55(80.9 \%)$ cases.

Table 1

General and clinical profile of study population

\begin{tabular}{lr}
\hline Characteristics & $\mathrm{n}(\%)$ \\
\hline Education level & \\
No schooling or primary schooling only & $17(25.0)$ \\
Secondary & $28(41.2)$ \\
Higher & $23(33.8)$ \\
History of early marriage (<16yrs) & $37(54.4)$ \\
Mean age at marriage (SD) & $19.8(4.29)$ \\
Age of 1st coitus & \\
$<20$ & $19(27.9)$ \\
$21-25$ & $27(39.7)$ \\
$>25$ & $20(29.4)$ \\
Parity & \\
1 & $17(25.0)$ \\
2 & $21(30.8)$ \\
3 & $19(27.9)$ \\
$4+$ & $11(16.2)$ \\
History of contraceptive methods* & \\
Oral contraceptive pills & $39(57.4)$ \\
Barrier method/Condoms & $43(63.2)$ \\
Intrauterine devices & $02(2.94)$ \\
Clinical manifestation* & \\
Irregular per vaginal bleeding & $23(33.8)$ \\
Post coital bleeding & $31(45.6)$ \\
Dyspareunia & $37(54.4)$ \\
Excessive vaginal discharge & $17(25.0)$ \\
Per speculum examination & $43(63.2)$ \\
Unhealthy cervix & \\
Enlarged/hard/friable/fixed & cervix/others \\
25 (36.8) &
\end{tabular}
25(36.8)

Note: *Many patients had more than 1 criteria; thus the total exceeds the total number of patients,

Table-I shows the general and clinical profile of the study patients. The educational level was high in 23 (33.8\%) patients; $28(41.2 \%)$ patients had secondary education and $17(25.0 \%)$ patients had no schooling or primary schooling only. A total of 37 (54.4\%) patients had history of early marriage. Mean age at marriage was $19.8 \pm 4.29$ years. 
Bang Med J Khulna 2013; 46

Among them, 19 (27.9\%) patients had history of early sexual relationship and $11(16.2 \%)$ were multipara (more than 4). History of using contraceptive methods revealed that 39 (57.4\%) patients had history of taking oral contraceptive pills (OCP), 43 (63.2\%) patients used condoms and $02(2.94 \%)$ patients used intrauterine devices. Among the clinical manifestations, 23 (33.8\%) patients had complaints of irregular per vaginal bleeding, while 31 (45.6\%), 37 (54.4\%) and 17 (25.0\%) had post-coital bleeding, dyspareunia and excessive vaginal discharge respectively. On per speculum examination, unhealthy cervix was observed in $43(63.2 \%)$ patients while 25 (36.8\%) patients had other problems e.g. dysuria, urinary incontinence, etc.

Table II

The correlation of socioeconomic class with HPV-DNA test

\begin{tabular}{lll}
\hline $\begin{array}{l}\text { Socioeconomic } \\
\text { Class }\end{array}$ & $\begin{array}{l}\text { Total } \\
(\mathrm{n}=68)\end{array}$ & $\begin{array}{l}\text { HPV DNA } \\
\text { positive (\%) }\end{array}$ \\
\hline High & 48 & $6(12.5)$ \\
Middle & 14 & $3(21.4)$ \\
Low & 6 & $4(66.6$ \\
\hline
\end{tabular}

The correlation of socioeconomic class with HPV DNA status among the cases is shown in Table-II. Among the 48 cases of high socioeconomic status, $6(12.5 \%)$ were HPV DNA positive, $3(21.4 \%)$ out of 14 middle class cases were HPV DNA positive, while $4(66.67 \%)$ women from low status were HPV DNA positive.

\section{Discussion:}

Human papilloma virus (HPV) is the most prevalent virus involved in sexually transmitted diseases worldwide, and an important public health challenge for the prevention of cervical carcinoma. ${ }^{18}$ It is considered as the main cause of most cervical cancers and cervical intraepithelial neoplasia (CIN). ${ }^{19}$ Thus, diagnosis of HPV at early stage of the infection is of fundamental importance in order to prevent progression of lesions and thereby decrease the number of cervical cancer related mortality.

The prevalence of HPV is related to some risk factors. In this study, $54.4 \%$ of the total study population had history of early marriage. Previous epidemiologic studies observed that the risk of cervical cancer was especially high among women marrying at young ages. In our study, a total of $57.4 \%$ patients had history of taking oral contraceptive pills; while $63.2 \%$ patients used condoms for contraception. A majority of studies indicate that long-term oral contraceptive pill users are at risk of cervical cancers. ${ }^{21,22}$ Oral contraceptive pills, Parity and perhaps other variables play important roles in the progression of low grade to high grades of neoplasia. ${ }^{23}$ Most of the time, early cervical cancer has no symptoms. Most of the patients come with abnormal vaginal bleeding or discharge, dyspareunia, postcoital bleeding. Preventing all these risk factors for HPV infection is a primary focus programs aimed at reducing cervical cancer incidence and morality. Modifiable and non modifiable risk factors for HPV infection include demographic, socioeconomic factors, sexual activity and life style.

In our study, only $13(19.1 \%)$ is HPV DNA positive, out of 68 cases of suspected cervical carcinoma. This result reflects a low prevalence of HPV in the study population in comparision to other studies.16,19,22 This low rate may be related to the sociocultural background, low incidence of extramarital sex and custom, family bonding \& deep rooted religion etc. which exist in this country. The overall and age-specific prevalence of HPV among women appears to vary by countries, region within countries and population subgroups. In Latin America, the frequency range was between $15 \%$ and $16 \%$ in Mexico, Costa Rica and Colombia. ${ }^{24-26}$ Large studies have found 16.7 per cent of all screened women to be HPV DNA positive. ${ }^{27}$ These geographical variations may be due to the prevalence of different subtypes of HPV and host related factors. Moreover, demographic, cultural, socioeconomic variables, multiparity, long term contraceptive use, young age at first coitus, multiple sexual partners, low socioeconomic status, low education level, poor genital hygiene, cigarette smoking, genital tract infections etc, are probable co-factors that increase the risk of cervical cancer in women with HPV infection. 23,24

Another important finding in the present study was the low socioeconomic condition which is highly associated with HPV infection (Table-II). Descriptive and analytic studies have demonstrated that cervical cancer predominantly affects women with low socioeconomic classes. $23-25$ This is most probably due to mal-nutrition, multiparity, multiple-sexual partners, early sexual exposure, concurrent genital infections, and lack of education. Sample size of this study is small due to its high cost and lack of awareness of HPV infection in suspected cervical carcinoma patients. However, further extensive studies with larger sample size should be carried out for confirmation of these findings.

\section{Conclusion:}

There is close association between HPV infection and invasive cancer. Therefore identification of high risk type could be an important tool for screening of carcinoma cervix. Primary screening 
Bang Med J Khulna 2013; 46

procedure if not reliable and feasible for developing country, HPV-DNA test can strengthen the result.

\section{References}

1. Mufioz N. Human papillomavirus and cancer: the epidemiological evidence. J Clin Virol 2000; 19: 1-5.

2. Lorincz, AT, Reid R. Association of Human papilloma virus with gynecologic cancer. Curr Opi Oncology 1989; 1:123-32.

3. Koutsky LA, Holmes KK, Critchlow CW, Stevens $\mathrm{CE}$, Paavonen J, Beckmann AM, et al. A cohort study of the risk of cervical intraepithelial neoplasia grade 2 or grade 3 in relation to papillomavirus infection. N EnglJ Med 1992; 327:1272-78.

4. Walboomers JM, Jacobs MV, Manos MM, Bosch FX, Kummer JA, Shah KV, et al. Human papillomavirus is a necessary cause of invasive cervical cancer worldwide. J Pathol 1999; 189: 1219.

5. Mufioz N, Bosch FX, Castellsague X, Diaz M, Sanjose $S$, Hamouda D, et al. Against which human papillomavirus types shall we vaccinate and screen? The International perspective. Int $\mathrm{J}$ Cancer 2004; 111: 278-85

6. Parkin DM. Cancer attributable to infection in the UK in 2010. Br J Cancer 2011; 105(S2): S6S13.

7. Parkin DM, Bray F, Ferlay J, and Pisani P. Estimating the world cancer burden: Globocan 2000. IntJ Cancer 2001; 94(2): 153-56.

8. Dunne EF, Vnger ER, and Sternberg M. Prevalence of HPV infection among females in the United States. JAMA 2007; 297(8):813-19.

9. Sankarnarayananan R, Bhatla N, Gravitt PE, Basu P, Esmy PO, Ashrafunnessa KS, Ariyaratne Y, Shah A, and Nene BM. Human papillomavirus infection and cervical cancer prevention in India, Bangladesh, Sri Lanka and Nepal. Vaccine 2008; 26S: M43-M45.

10. Akhter PS, Uddin MM, and Sharma SK. Patterns of malignant neoplasm- a three years study. Bangladesh Medical Journal 1998; 27(2): 29-32.

11. Sharma RG, Ajmera R, and Sexena O. Cancer profile in eastern Rajasthan. Indian $J$ Cancer 1994; 31 : 160-73.

12. Munoz N, Franceschi S, Bosetti C, Moreno V, Herrero R, Smith IS, et al. Role of parity and human papillomavirus in cervical cancer: The IARC multicentric case-control study. Lancet 2002; 359: 1093-01.

13. S.Moreno V, Bosch FX, Munoz N, Meijer CJ, Shah KV, Walboomers IM, el al. Effect of oral contraceptives on risk of cervical cancer in women with human papillomavirus infection: The IARC multicentric case-control study. Lancet 2002; 359: 1085-92.

14. Blomberg M, Friis S, Munk C, et al. Genital warts and risk of cancer: a denish study of nearly 50000 patients with genital warts. JInfect Dis 2012; 205(10): 1544-53.

15. Khan MJ, Partridge EE, Wang SS, Schiffman M. Socioeconomic status and the risk of cervical intraepithelial neoplasia grade 3 among oncogenic human papillomavirus DNA-positive women with equivocal or mildly abnormal cytology. Cancer 2005; 104(1): $61-70$
16. Rushton L, Bagga S, Bevan R, et al. Occupation and cancer in Britain. Br $\mathrm{J}$ Cancer 2011; 102: 1428-37.

17. Digene Corporation. hc2 High-Risk HPV DNA Test. (pp. 1-49). USA. 2006.

18. Skerlev M, Giri M, and Skerlev HS. Human Papillomavirus male genital infections: Clinical variations and the significance of DNA typing. Clinics Dermatol 2002; 20: 173-78.

19. Munoz N, Bosch FX, and de Sanjose, S. Epidemiologic classification of human papillomavirus types associated with cervical cancer. NEng JMed, 2003; 348: 518-27.

20. Jones EG, MacDonald J, and Brewslow L. A study of epidemiologic factors in carcinoma of the uterine cervix. Am J Obstet Gynecol 1958; 76: 1-10.

21. Schiffman MH, Bauer HM, Hoover RN, Glass AG, Cadell DM, Rush BB, Scott DR, Sherman ME, Kurman RJ, Wacholder S, Stanton CK, and Manos MM. Epidemiologic Evidence Showing That Human Papillomavirus Infection Causes Most Cervical Intraepithelial Neoplasia. J Natl Cancer Inst 1993; 85(12): 958-64.

22. Adam E, Berkova $Z$, Daxnerova, $Z$, Icenogle $J$, Reeves, WC and Kaufman RH. Papillomavirus detection: demographic and behavioral characteristics influencing the identification of cervical disease. Am J Obstet Gynecol 2000; 182: 257-64.

23. Brinton LA, Hamman RF, and Huggins GR. Sexual and reproductive risk factors for invasive squamous cell cervical cancer. J Natl Cancer Inst 1987; 79: 23-30.

24. Morrison H. Human papillomavirus absence predicts normal cervical histopathologic findings with abnormal papanicolaou smears. J Hum Virol 1993; 4: 283-7.

25.Lazcano E, Herrero R, Munoz N, Cruz A, Shah K, Alonso P, et al. Epidemiology of HPV infection among Mexican women with normal cervical cytology. Int J Cancer 2001; 91: 412-20.

26. Herrerro R, Hildesheim A, Bratty C, Sherman M, Mutchinson M, Mlrales J, et al. Population-based study of human papillomavirus infection and cervical neoplasia in rural Costa Rica. JNatl Cancer Inst (Bethesda) 2000; 92: 464-74.

27. Cogliano VJ, Baan R, Straif K, et al. Preventable exposures associated with human cancers. JNCI 2011; 103: 1827-39.

28. Parkin DM, Boyd L, Walker LC. The fraction of cancer attributable to lifestyle and environmental factors in the UK in 2010. Summary and conclusions. Br J Cancer 6 Dec 2011; 105(S2): S77S81.

29. Szarewski A, Poppe W, Skinner S; et al. Efficacy of the human papillomavirus (HPV)-16/18 ASO4adjuvanted vaccine in women aged 15-25 years with and without serological evidence of previous exposure to HPV-16/18. Int J Cancer 2012; 131(1): 106- 16.

30. Cogliano VJ, Baan R, Straif K, et al. Preventable exposures associated with human cancers. JNCI 2011; 103: 1827-39 